Anales de Literatura Hispanoamericana

ISSN-e: 1988-2351

\title{
Bregando con la voz de su amo. La amante de Gardel de Mayra Santos-Febres
}

\author{
Rita de Maeseneer ${ }^{1}$ y Manochak Milkon ${ }^{2}$
}

Resumen. La escritora puertorriqueña Mayra Santos-Febres siempre ha demostrado un gran interés por las manifestaciones de la música popular y más particularmente la caribeña, a la vez que ha sido una gran defensora de la mujer negra. En La amante de Gardel (2015), novela ubicada en Puerto Rico, la protagonista es Micaela Thorné, curandera y primera mujer negra médica, rememora en su lecho de muerte su vida y su romance ficticio en 1935 con Gardel cuyo pasado también es narrado. Opinamos que Mayra Santos-Febres utiliza la figura de Gardel para bregar con varias inquietudes recurrentes en su obra: Gardel como expresión de lo pan-latino, Gardel como mito popular, Gardel y el poder de la voz, Gardel como gramófono de los sin voz, Gardel como ícono masculino que somete a la mujer. Por tanto, la novela ofrece más pistas que la mera explotación comercial de un ícono.

Palabras clave: cultura popular; Carlos Gardel; Mayra Santos-Febres; gender; literatura puertorriqueña.

\section{[en] Coping with his master's voice. Gardel's lover by Mayra Santos-Febres}

\begin{abstract}
The Puerto Rican writer Mayra Santos-Febres has always shown a great interest in the expressions of popular music and the Caribbean rhythms in particular. Moreover, she has always been a defender of black women. In $L a$ amante de Gardel (2015), a novel that takes place in Puerto Rico, the protagonist is Micaela Thorné, a healer and the first black doctor. On her death bed she recalls her life and her fictitious romance with Carlos Gardel whose past is also narrated. We argue that Santos-Febres uses the character of Gardel to cope with different recurrent concerns in her work: Gardel as an expression of pan-latinism, Gardel as a popular myth, Gardel and the power of the voice, Gardel as a gramophone for the voiceless, Gardel as a male icon who subjugates women. In doing so, the novel offers more perspectives than a simple commercial exploitation of an icon.
\end{abstract}

Keywords: popular culture; Carlos Gardel; Mayra Santos-Febres; gender; Puerto Rican literature.

Sumario: 1. Introducción. 2.Gardel como expresión de lo pan-latino. 3. Gardel como mito popular. 4. Gardel y el poder de la voz. 5. Gardel como 'gramófono' de los sin voz. 6. Gardel como ícono masculino que somete a la mujer. 7. Conclusión.

Cómo citar: De Maeseneer, R. y Milkon, M. (2021) Bregando con la voz de su amo. La amante de Gardel de Mayra Santos-Febres, en Anales de Literatua Hispanoamericana 50, 247-254.

\section{Introducción}

Mayra Santos-Febres (1966) se dio a conocer a nivel internacional con Sirena Selena vestida de pena (2000), una novela sobre un travesti, cantante de boleros. Efectivamente, una constante preocupación en su trayectoria la constituyen las manifestaciones de la música popular, sobre todo la caribeña. Además, siendo una de las pocas escritoras negras de Puerto Rico, siempre ha defendido a la mujer negra. Confiesa Mayra Santos-Febres: "Definitivamente, todo lo que escribo lo hago desde la perspectiva de una mujer caribeña negra, con visión y ambición diaspórica y universal. ¿Puede ser de otra manera?” (Anónimo, 2014: s.p.).

En La amante de Gardel (2015), novela ubicada en Puerto Rico, se ven reunidos estos dos puntos de interés de la escritora. La protagonista es Micaela Thorné, curandera y primera mujer negra médica.

\footnotetext{
1 Universiteit Antwerpen. Bélgica.

E-mail: rita.demaeseneer@uantwerpen.be

${ }^{2}$ Universiteit Antwerpen. Bélgica.

E-mail: milkon.manochak@gmail.com
} 
Rememora en su lecho de muerte su vida y su romance ficticio de 27 días en abril de 1935 con Gardel cuya vida pasada también es evocada. Micaela entró en contacto con el cantante al acompañar a su abuela curandera. La ayuda de la abuela fue solicitada para curar con sus plantas mágicas los problemas de voz de Gardel, provocados por su sífilis (que Gardel nunca tuvo en su vida real). Alternan los capítulos centrados en Micaela con las confidencias autobiográficas que Gardel contó a Micaela en sus trances inducidos por una poción hecha en base a corazón de viento. Aunque solo una cuarta parte de la novela está dedicada a enfocar la vida de Gardel (54 páginas de las 197) y el énfasis está en Micaela y su lucha como mujer negra en un contexto puertorriqueño de modernización, ${ }^{3}$ no dejan de intrigar la presencia de Gardel y su mención desde el título. Nuestro propósito consiste en investigar la manera como Gardel es presentado en la novela y qué funcionalidad(es) podría tener. Visto que muchos críticos coinciden en el hecho de que Gardel es una figura inaprensible de por sí, ${ }^{4}$ nuestra propuesta de lectura es que en La amante de Gardel Mayra Santos-Febres aprovecha esta maleabilidad del Zorzal Criollo para ofrecernos una aproximación muy acorde con sus preocupaciones artísticas e ideológicas. Más particularmente, nos interesa demostrar que la escritora utiliza la figura de Gardel para tratar varias inquietudes recurrentes en su obra: lo transnacional, la identidad performática, la sonoridad-oralidad, la subalternidad y la mujer. ${ }^{5}$ Por tanto, reflexionaremos sobre Gardel desde cinco puntos de interés que se desprenden de la novela: Gardel como expresión de lo pan-latino, Gardel como mito popular, Gardel y el poder de la voz, Gardel como 'gramófono' de los sin voz, Gardel como ícono masculino que somete a la mujer. De esta manera la novela ofrece muchas más pistas que la mera explotación comercial de un ícono que siempre vende, tal como podría deducirse del paratexto (el título y la portada con la foto de Gardel). ${ }^{6}$

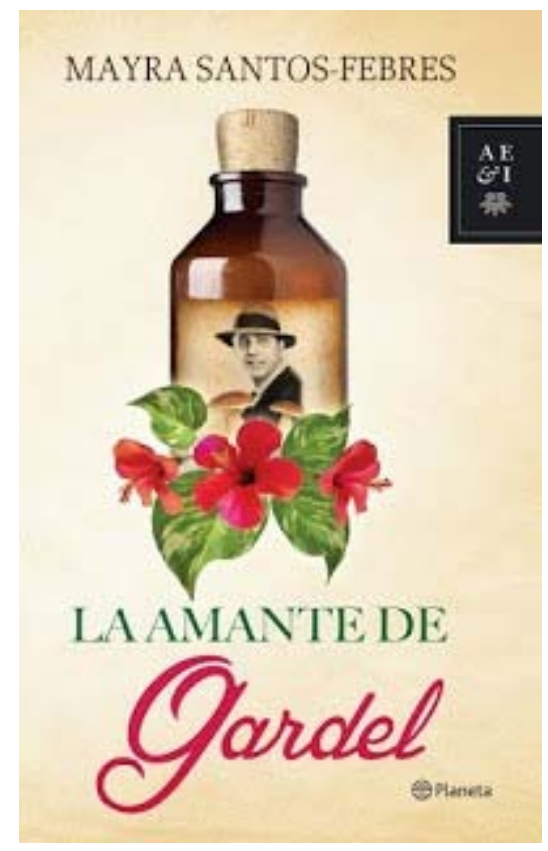

Cubierta de la novela

\footnotetext{
${ }^{3}$ Algunos reseñistas recalcan la entrada en la modernidad en la década del treinta, por ejemplo: "The career of Carlos Gardel and his time in Puerto Rico mark the modernization of this Caribbean island as an experimental space for performances that would later spread throughout Latin America" (Torres, 2017: s.p.). No solo se manifiesta en el tango, un ejemplo da las modernidades primitivas según Garramuño (2007), sino también en experimentos médicos como el del doctor Rhoads (1931) quien infectó con cáncer al "puertorriqueño convertido en objeto de la ciencia bajo el pretexto del progreso de la medicina y la modernización” (Lladó Ortega, 2016: s.p.).

4 "His identity is manipulable, malleable, and infinitely adaptable due to its changeability" (Misemer, 2008: 48).

${ }^{5}$ Estos enfoques son constantes en la bibliografía secundaria, por ejemplo, en el hasta ahora único volumen dedicado exclusivamente a la obra de Mayra Santos-Febres, coordinado por Nadia Celis y Juan Pablo Rivera.

${ }^{6}$ No descartamos que Santos-Febres haya aprovechado el potencial de marketing que conlleva la figura de Gardel. La autora no rehúye el mundo comercial, sino que recurre a él de modo estratégico, no solo para promocionar su obra, sino también la literatura puertorriqueña muy invisibilizada. Por ejemplo, ha organizado durante varios años el Festival de la Palabra con el apoyo de universidades, instituciones culturales y empresas como Audi.
} 
Antes de indagar en estas funcionalidades, cabe observar que Santos-Febres sigue de modo bastante cronológico la trayectoria del Morocho del Abasto en su novela. Así Gardel empieza por referirse a su nacimiento en Francia, por lo que se adhiere a la hipótesis francesista y no uruguayista. ${ }^{7}$ Luego la escritora se detiene en su vida en el barrio del Abasto, el contacto con el cantante uruguayo Razzano y con el Negro Ricardo, uno de sus arreglistas y músicos a quien presta mucha atención en la intriga. Describe los giros por América Latina, Europa y Estados Unidos hasta llegar al tiempo del discurso, los 27 días en 1935. Un cotejo superficial de los eventos evocados en la novela con algunas biografías del cantante muestra que SantosFebres procedió por una selección de datos factuales bastante conocidos, pero también añadió elementos ficticios. ${ }^{8}$ Se inventa unos hechos que no están atestiguados en ninguna fuente. A este respecto, la fabulación más llamativa es por supuesto la historia de la sífilis de Gardel, una enfermedad nunca contraída por él (pero sí por Pascual Contursi, su letrista). La misma estrategia de usar a Micaela como narradora en su lecho de muerte permite arrojar un (doble) filtro sobre lo supuestamente relatado por Gardel. Micaela comenta al inicio de la novela: "Lo que narro no es exactamente lo que me contó; narro otra cosa" (Santos-Febres, 2015: 15). ${ }^{9}$ Veamos ahora cuáles son las cinco funcionalidades de la integración de este famoso cantante en el texto.

\section{Gardel como expresión de lo pan-latino}

A diferencia de muchos otros escritores puertorriqueños obsesionados con la identitis y el insularismo (Duchesne-Winter, 2007), el enfoque transcaribeño y transnacional siempre ha caracterizado la escritura de Mayra Santos-Febres, por ejemplo al ubicar gran parte de Sirena Selena en Santo Domingo. La amante de Gardel se desarrolla en Puerto Rico evocando la gira de Gardel por la isla en 1935, pero la escritora rebasa este marco geográfico, entre otras estrategias, mediante la incorporación del tango y la figura de Gardel. ${ }^{10} \mathrm{Al}$ igual que la mayoría de los géneros de la música popular latinoamericana (danzón, bolero, son), el tango es transnacional en sus orígenes, "[e]s el baile híbrido de gente híbrida: tiene algo de habanera traída por los marineros, restos de milonga y luego mucho de música italiana. Todo entreverado, como los músicos que lo inventan: criollos como Poncio y gringos como Zambonini” (Sábato, 1963: s.p.).

A pesar de que el tango es de producción casi exclusivamente argentina, su mayor representante, de origen transnacional, hizo que este género musical se convirtiera en una expresión pan-latina: "Gardel is becoming a transnational figure, crossing cultural and political borders in Latin America and even Spain" (Misemer, 2008: 47). Insertando la figura de Gardel y más específicamente sus giras internacionales, Mayra Santos-Febres cuenta la historia de una comunidad pan-latina.

\section{Gardel como mito popular}

Otro punto de interés en los escritos de Mayra-Santos Febres es la reflexión sobre la identidad performática, el ser y el estar, lo cual se manifiesta de modo muy extremo en la novela sobre el travesti Sirena Selena. Se podría relacionar este enfoque con la representación de Gardel como mito. Es un mito en el sentido tradicional, es decir relacionado con dioses y cosmogonías, y en el sentido semiótico tal como lo expuso Barthes en Mythologies (1957). Para él los mitos son sistemas de comunicación que se pueden manifestar en objetos, entes seculares o religiosos, y representan una cultura o una ideología.

${ }^{7}$ La primera hipótesis defiende que nació en Toulouse, Francia, el 11 de diciembre de 1890. Según otros, nació en Tacuarembó, Uruguay, el 11 de diciembre de 1887. Existe una ingente bibliografía sobre ambas hipótesis.

${ }^{8}$ Mayra Santos-Febres no solo se toma libertades con la historia de Gardel, sino también con la de Puerto Rico, por ejemplo, al mencionar varias calles no existentes en 1935. Véase la reseña de Carmen Dolores Hernández quien apunta varios anacronismos e inexactitudes. Por lo que hemos podido averiguar, la figura de Micaela Thorné no es histórica. De todas formas, llama la atención que al incursionar en el pasado Santos-Febres se enfoca en figuras femeninas que no pertenecen a la Historia con mayúscula, sino a la intrahistoria. Pensemos en Xica da Silva, una esclava negra del siglo XVIII investigada por la historiadora Fe Verdejo en Fe en disfraz (2009), o en Isabel Luberza Oppenheimer, la dueña de un prostíbulo de Ponce, que inspiró a la protagonista de Nuestra señora de la noche (2006), otra novela ambientada en los años 30. Santos-Febres comentó en una entrevista que estaba trabajando en otra novela "histórica": "Hace siete años trabajo la tercera novela de mi saga histórica "Pecho Seco" que se basa en la vida de la primera mujer condenada a muerte en Puerto Rico, la sirvienta Luisa Nevares Ortiz” (Anónimo, 2014: s.p.).

${ }^{9}$ De ahora en adelante solo citaremos la página.

${ }^{10}$ La misma Micaela es transnacional, ya que se refiere a sus "ancestros mulatos, pastores episcopales de la isla de la Trinidad" (43). 
El 'Mago' (Gardel) se parece a un dios de la mitología clásica, inasible y siempre cambiante. En "San Gardel, comediante y mártir" Blas Matamoro indaga en los hechos que lo llevaron a esta supuesta santidad, por ejemplo, las variadas conjeturas tejidas en torno a su origen. Matamoro concluye: "Gardel parece haber pasado por los infiernos y llegado al cielo y, para completar su hagiografía, tenemos el evento de su muerte sacrificial en un accidente de aviación" (1984: 40). Gardel no solo murió, sino que también vivió como una performance, porque no había mucha gente que lo conociera de verdad. En varios momentos en el libro Micaela subraya las diferentes caras de Gardel: el Gardel del escenario, el Gardel de la cama, el Gardel de las películas, el Gardel de las fotos...

Ruffinelli insiste asimismo en las diferentes versiones que se crearon alrededor de Gardel, fomentados por la ambigüedad y el carácter reservado del cantante: el Gardel delincuente, el Gardel homosexual, el Gardel francés o el Gardel uruguayo. El crítico llega a defender la hipótesis de que Gardel fue revelando más de su vida en sus últimas películas al establecer interesantes paralelismos entre la vida de Gardel y sus papeles en El día que me quieras o Tango bar, ambas de 1935. La versión fílmica de Gardel revela más que la persona real. Estas diferentes versiones y las discusiones sobre su vida alimentan el mito de Gardel y de esta manera le otorgan a su identidad una dimensión inestable y performática.

Gardel tenía sus secretos que eran muy bien guardados. Era una aparición durante sus actuaciones, casi una epifanía, pero nadie sabía lo que pasaba detrás de esta máscara con la que subía al escenario. Observa Misemer:

Theatricality is an inherent quality in Gardel. Throughout his career, he fostered various public and private images. His persona is an artistic creation just as much as are his musical recordings and film appearances. Even Gardel's 'real' identity is a much discussed and disputed question in Argentina and Uruguay. (2008, 38)

Por tanto, Gardel es una performance constante, un simulacro, siempre está escondido detrás de sus múltiples máscaras.

\section{Gardel y el poder de la voz}

Visto el contexto caribeño, caracterizado por una gran presencia de la cultura oral, no es de extrañar que la voz y la sonoridad ocupen un lugar central en la poética de Mayra Santos-Febres. En esto sigue a uno de sus grandes ejemplos, Édouard Glissant, y su énfasis en la oralidad y sus efectos en lo escrito en el contexto antillano. El pensador martiniqués ha venido repitiendo esta idea a lo largo de su trayectoria. Por ejemplo, escribe en Traité du Tout-Monde: “Écrire c'est vraiment dire: s'épandre au monde sans se disperser ni s'y diluer, et sans craindre d'y exercer ces pouvoirs de l'oralité qui conviennent tant à la diversité de toutes choses" (Glissant, 1997: 121). En su obra Santos-Febres presta mucha importancia a la dimensión auditiva y oral. La escritora boricua posee un talento particular para describir la manera como los sonidos van adquiriendo una fuerza trascendental y de hechizo en el público. La voz es un arma de seducción (en el sentido de Baudrillard, 1979) e implica poder. Micaela, que no es una gran fanática del tango, es embelesada completamente por las canciones de Gardel cuando asiste a su actuación en el teatro Paramount:

Miel espesa. Densidad de almizcle. Las ondas de su voz me llegaron como un baño de ungüentos; una caricia untada con algo. Aquello no era el rayado distante de los discos que sonaban en las vitrolas de Campo Alegre, ni la voz de la radio que hacía que una se concentrara en mensajes y melodías. Aquella noche en el Paramount la voz de Gardel estaba viva. Era una reverberación robusta pero clara con dientes y con garras que no incitaba al desgarre ni a devoramiento, que convidaban a posar el pie, al cuerpo entero sobre el aire, para viajar lejos hacia adentro.[...] Se acrecentó esa extraña resonancia en mi pecho que era, el mismo pecho de Gardel, la garganta de Gardel, su aire. Poco a poco se fue tejiendo una complicidad. (64)

La voz de Gardel (declarada patrimonio de la humanidad en 2003 por la Unesco) no solo la embauca al cantar sino también al hablar, contar, tranquilizar, convencer. Gardel sabe muy bien cómo utilizar la voz: para ganar la simpatía de otros, para obtener dinero, para convencer a los músicos a tocar con él, para seducir a Micaela aunque no la amaba, porque ella tenía que curarle, para entretener a la gente y llegar a sus corazones. La voz de quien paradójicamente fue apodado también el Mudo es su esencia. Es lo único que conoce la gente del campo a la que aún no habían llegado las películas con su ídolo. Encima, la voz es un bálsamo para la gente. Lladó Ortega retoma lo advertido en la novela (59-60) al observar que "la resonancia 
de su voz, que habita el ámbito del corazón humano [...] se presenta como otro remedio que cura las almas de las personas" (2016: s.p).

\section{Gardel como 'gramófono' de los sin voz}

Que se trate de los yoleros en su poemario boatpeople (2005) o de una esclava negra en la novela Fe en disfraz (2009), llama la atención el protagonismo de los subalternos en los textos de Santos-Febres, contemplados sobre todo en sus dimensiones social y racial. En una entrevista la autora subrayó que quería destacar esta vertiente subalterna social: "Gardel es la historia de nosotros, de la migración mexicana, dominicana, madre soltera lavandera, migrante que entró sin papeles" (Lavín, 2016: s.p.). En la novela es privilegiada la asociación con los de abajo por la insistencia en el origen humilde del cantante que él mismo recalcaba también con frecuencia en sus entrevistas. Es lo que le une a Micaela según Gardel: "Me gusta donde vivís allá en la ciudad; Se parece al lugar donde me crié" (88). A pesar de que ya se ha convertido en un hombre rico, quiere seguir siendo la voz de los sin voz dando conciertos por toda la isla a precios módicos "[p]ara que vaya la gente humilde, gente a quien Gardel jamás olvidó" (22). En sus recuerdos Gardel habla de un concierto de caridad que se organizó después de un huracán que azotó la Martinica: “Je voudrais chanter pour ces pauvres gens - le dije al dueño -. Je donnerai ma voix, mes chansons.' De gratis y para salvar" (153).

En cuanto a la subalternidad racial, parece menos evidente a primera vista. Como es sabido, Gardel era blanco, lo llamaron el Morocho del Abasto, no en el sentido de moreno, sino en el sentido del que tiene el pelo negro. Aunque es harto sabido que el criterio biológico del color de la piel no explica únicamente actitudes de discriminación y primitivización del otro, se insiste en presentarnos a un Gardel más cercano a lo negro. En cierto momento Gardel constata que tiene los brazos menos blancos que su madre:

Niño rechoncho y rabioso. Niño oscuro y gordo con el pelo muy negro. Él mismo se describió. Su madre era pálida, muy pálida. -¿A quién salí tan trigueño, Maman? ¿Por qué no soy como tú? -Ese es mi color de adentro -me contó que contestó su madre y unió su piel a la mía, como si estuviera hablando con ella. - Ves cómo se me escapa el color; cómo tiñe mis brazos. (32)

Una prueba más manifiesta de la importancia de la cuestión racial se encuentra en el hecho de que en la narración desempeña un papel protagónico el Negro Ricardo. Para explicar la misteriosa ruptura entre Gardel y el Negro Ricardo en 1927, no es mencionado el racismo, al menos en las fuentes que consultamos, a diferencia de lo que se sugiere en la novela. ${ }^{11}$ También refuerza la vertiente racial el mismo género del tango cuya impronta africana a causa de los ritmos de la habanera afro-caribeña y el candombe negro ha sido señalada por varios estudiosos (Chasteen, 2000; Plisson, 2001; Thompson, 2005). De ahí que Misemer sugiera la siguiente cadena de asociaciones: "Tango-eroticism-roots-sexuality-primitiveness-blackness" (2008: 50). Aunque le desagrada bastante a Micaela por lo estereotípico, Gardel relaciona el tango con la negritud que ella encarnaría, aunque no es negra negra: "Y el tango es negro, no del todo, pero también. Cele Flores, el Negro Ricardo lo hicieron, todos juntos lo hicimos nacer. ¿No llevás ese ritmo en la sangre?" (108). Sea como sea, Gardel está puesto del lado del subalterno, el pobre, el negro.

\section{Gardel como ícono masculino que somete a la mujer}

En cuanto al gender, uno de los focos más constantes en Mayra Santos-Febres, La amante de Gardel, este sintagma que incluye un complemento 'posesivo', parece construida sobre una curiosa paradoja. Por un lado, reivindica la autonomía de la mujer, ya que Micaela Thorné ejemplifica a la mujer independiente y se convierte en la primera médica negra que participa en experimentos científicos. Así cumple al cien por cien con la agenda feminista de Santos-Febres. Por otro lado, Mayra Santos-Febres asimila a Gardel con la imagen machista, tan típica de muchos cantantes de música popular. Pensemos en Daniel Santos cuyo

\footnotetext{
${ }^{11}$ Una de las versiones señala que fue por cansancio y porque vivió con una blanca francesa (http://mundogardeliano.blogspot.be/2015/08/el-negroricardo-su-pelea-con-gardel.html). Otra fuente explica la ruptura por el disgusto de Ricardo con el protagonismo instrumental que pretendía José María Aguilar, otro guitarrista (http://www.todotango.com/creadores/biografia/105/Jose-Ricardo/).
} 
machismo es recalcado (y subvertido) en la novela La importancia de llamarse Daniel Santos (1989) de Luis Rafael Sánchez o en Agustín Lara, cuya "entrega saqueable a las mujeres" es recalcada por Carlos Monsiváis $(1993,61)$. No incursiona en las ambigüedades sexuales que fueron sugeridas respecto a Gardel cuya adoración por la madre y su relación con la eterna novia Isabel del Valle levantó sospechas de homosexualidad. Tampoco matiza su actitud hacia las mujeres a quienes a veces compadece en sus canciones. Micaela, de su lado, se coloca en un papel de dependencia total de Gardel en lo emocional: "Yo era su presa, su espécimen; el objeto de su afecto" (114). Es Gardel quien la atrae, quien decide, quien delega la mala noticia del final del amorío en el empresario de la gira. ${ }^{12}$ Parece haber desvanecido por completo su papel de mujer autónoma e igual al hombre. No obstante, si se mira la relación de modo más detenido, se puede argüir que Santos-Febres ha intentado dotar de cierta agencia a la mujer e incluso cuestionar el papel dominante de Gardel en la relación. Se podría hablar de una sumisión recíproca muy deliberada, una suerte de negociación no exenta de intereses particulares: mientras Gardel la necesita para mantener su voz, Micaela lo utiliza de cierto modo para distinguirse de sus antepasados. Gardel le hace creer a Micaela que se somete a ella, pero el propósito es que le cure bien. Micaela se entrega a Gardel por unas razones bien particulares: liberarse de lo tradicional de su familia (rebelarse contra las reglas), escapar de la pobreza (vivir momentáneamente en el lujo), salir de la sombra de la mujer negra sometida (cambiar como persona y decidir que nadie es mejor que ella, por eso baja las escaleras grandes del hotel dos veces y no toma la escalera de servicio reservada a la plantilla negra), tener tiempo libre para pensar y leer cuando está esperando a Gardel. Santos-Febres otorga cierta agencia a la mujer incluso dentro de una relación sumamente patriarcal.

Esta situación paradójica corre paralela con lo que pasa en el tango (a diferencia de otros géneros populares como el bolero). En bastantes letras de tango es la mujer la que tiene una capacidad de decisión de abandonar al hombre (Lagmanovich, 2000: 115). Y en el baile, aunque es el hombre quien lleva a la mujer, ésta tiene una posibilidad de manipular un poco al hombre (Savigliano en Vilaltella, 2000: 40). La observación de Thompson, una de las fuentes usadas por Santos-Febres, va en el mismo sentido:

In a piece on tango in The New York Times, Janny Scott found that 'followers' (a eufemism for females) were told not to move until the 'leaders' indicated it was time. But she also discovered that tango women do not necessarily mirror what men are doing. 'They often do different steps.' How to comprehend the contradiction? Study the figures. In the ocho, a figure-eight pattern, with mirroring pivots, the woman moves back and forth in a sinuous sequence that is wholly her own. ... Ocho is a womanist original, set in motion by men. It is a call-and-response on the dance floor. (2005: 6)

La mujer, aunque dirigida por el hombre, impone a veces sus propios pasos. Contesta a lo que el hombre le dice. No solo sigue, sino que también actúa. Santos-Febres explora por tanto esta difícil posición de la mujer desgarrada, dividida entre sus emociones/lo corporal y la razón/lo cerebral y no puede deshacerse totalmente del reparto tradicional de los roles que vienen siendo asignados al hombre y a la mujer.

\section{Conclusión}

Mayra Santos-Febres se atrevió a enfrentarse a uno de los íconos evocados en un sinfín de biografías, ficcionalizaciones y películas. ${ }^{13}$ Dicho de otro modo, aceptó el reto de bregar con Gardel. Usamos muy deliberadamente 'bregar', este verbo muy puertorriqueño cuya polisemia exploró Arcadio Díaz-Quiñones en su ensayo "El arte de bregar". Bregar es un modo de gestión, un modus operandi que denota habilidad, pericia y la ausencia de una confrontación explícita. Es una manera de lidiar actuando con astucia, suavizando, manipulando que permite resolver y sobrellevar situaciones, de otro modo, insoportables o irresolubles. Así es como Santos-Febres se ha enfrentado al mito de Gardel: lo ha mitificado y desmitificado a la vez, proyectando sus preocupaciones sobre el cantante. Su manera particular de 'bregar' con la voz de su amo la ha llevado a forzar la imagen, sobre todo en relación con el gender y la raza.

\footnotetext{
${ }^{12}$ Parece que la estrategia de delegación para anunciar malas noticias era una constante en Gardel: su administrador tuvo que transmitir la ruptura de Gardel con Isabel del Valle para poner fin a su estatuto de novia eterna.

${ }^{13}$ Para un repaso, véase "Gardel en los ojos de los otros” y “Copia y falsificación (El caso de los Gardeles 'falsos””) (Ruffinelli, 2004: 85-151).
} 
Más allá del caso particular de Gardel, la novela nos invita a reflexionar sobre la importancia de los íconos y el stardom, fenómenos que en nuestra cultura del espectáculo van cobrando cada vez más importancia. En Sage Handbook of Popular Music se señalan cuatro condiciones que hay que reunir para convertirse en una estrella de verdad aparte de haber desarrollado una personalidad distintiva y consistente: ser exitoso en un campo que requiere talento; ser objeto de relaciones personales imaginarias por parte de los admiradores; ser atractivo sexualmente; representar más que una personalidad individual, ser un símbolo cultural ampliamente entendido (Shumway, 2015: 303). Sobre todo el último requisito es de destacar en el contexto latinoamericano donde la oralidad que se manifiesta en his master's voice tiene un impacto muy potente (y no solo en lo musical). Mayra Santos-Febres supo aprovechar tanto la versatilidad como el estatuto icónico de la figura de Gardel, sumamente pertinente para entender la complejidad de Puerto Rico, el Caribe y América Latina. A la vez, su novela ha contribuido a que Gardel nunca pierda la voz y perpetúe su relevancia cultural. Ya apuntó Braudy que uno de los elementos constitutivos de la fama es: "what posterity has thought about them ever since" $(1986: 15){ }^{14}$

\section{Referencias bibliográficas}

Anónimo (2014), “Mayra Santos y el poder de sus letras”, Mujerontop (june 7). Disponible en: http://www.mujeresontop.com/mayra-santos-y-el-poder-de-sus-letras/

Barthes, Roland (1957). Mythologies. Paris: Seuil.

Baudrillard, Jean (1979). De la séduction. Paris: Galilée.

Braudy, Leo (1986). The Frenzy of Renown. Fame \& Its History. New York-Oxford: Oxford University Press.

Celis, Nadia, Juan Pablo Rivera (eds.) (2011). Lección errante: Mayra Santos-Febres y el Caribe contemporáneo. San Juan: Isla Negra Editores.

Chasteen, John Charles (2000), "Black Kings, Blackface Carnival, and Nineteenth-Century Origins of the Tango", en William H Beezley and Linda A. Curcio-Nagy (eds.). Latin American Popular Culture. An Introduction. Wilmington: SR Books, págs. 43-59.

Díaz-Quiñones, Arcadio (2000), "De cómo y cuándo bregar”, en El arte de bregar. Ensayos. San Juan: Ediciones Callejón, págs.19-87.

Duchesne-Winter, Juan (2007), "Neonacionalismo y fatiga de identidad en Puerto Rico", Arbor. Ciencia, Pensamiento y Cultura CLXXXIII, 724 (marzo-abril), págs. 265-274.

Garramuño, Florencia (2007). Modernidades primitivas. Tango, samba y nación. Buenos Aires: Fondo de Cultura Económica.

Glissant, Édouard (1997). Traité du Tout-Monde (Poétique IV). Paris: Gallimard.

Hernández, Carmen Dolores (2015), "Cuando Gardel viajó a Puerto Rico", El Nuevo Día (22 de noviembre). Disponible en: https://www.pressreader.com/puerto-rico/el-nuevo-d\%C3\%ADa/20151122/282123520415700

Lagmanovich, David (2000), "Las letras de tango en el sistema literario argentino posterior al Modernismo: continuidad y ruptura”, en Michael Rössner (ed.). ¡Bailá! ¡Vení! ¡Volá! El fenómeno tanguero y la literatura. Madrid-Frankfurt: Iberoamericana-Vervuert, págs. 103- 122.

Lavín, Vivia (2016), "La amante de Gardel". Disponible en: http://www.vuelanlasplumas.cl/la-amante-de-gardel/vlp/2016-02-10/123501.html.

Lladó OrtEgA, Mónica (2016), "Las resonancias en La amante de Gardel de Mayra Santos-Febres", 80 grados, 22 de enero. Disponible en: http://www.80grados.net/las-resonancias-en-la-amante-de-gardel-de-mayra-santos-febres/

Matamoro, Blas (1984), "San Gardel, comediante y mártir", en Le tango. Hommage à Carlos Gardel. Colloque International de Toulouse. Toulouse: Université de Toulouse-le-Mirail, págs. 35-42.

Monsiváis, Carlos (1993). Amor perdido. México: Era.

Misemer, Sarah M. (2008). Secular Saints. Performing Frida Kahlo, Carlos Gardel, Eva Perón and Selena. Woodbridge : Tamesis.

Plisson, Michel (2001). Tango du noir au blanc. Paris/Arles: Cité de la Musique/Actes Sud.

Ruffinelli, Jorge (2004). La sonrisa de Gardel. Biografía, mito, ficción. Montevideo: Trilce.

Sábato, Ernesto (1963). Tango, discusión y clave. Disponible en: http://gatopistola.blogspot.be/2011/05/4-bandoneon-de-tango-discusion-y-clave.html

Sánchez, Luis Rafael (2000 [1989]). La importancia de llamarse Daniel Santos. San Juan: Editorial de la Universidad de Puerto Rico.

Santos-Febres, Mayra (2015). La amante de Gardel. México: Planeta.

\footnotetext{
${ }^{14}$ Agradecemos a Mayra Santos-Febres la ayuda para orientarnos en cuanto a las fuentes usadas por ella, a Dominique Casimiro el que nos haya permitido participar en su coloquio sobre Carlos Gardel el 18 y el 19 de mayo de 2017 en la Universidad de Arras, a Jorge Ruffinelli quien tuvo la generosidad de mandarnos su libro sobre Gardel gracias a la intervención de Ignacio Bajter.
} 
Torres, Daniel (2017), "La amante de Gardel by Mayra-Santos Febres". Latin American Literature Today (January). Disponible en:

http://www.latinamericanliteraturetoday.org/en/2017/january/la-amante-de-gardel-mayra-santosfebres

Shumway, David (2015), "Rock stars as icons", en Andy Benett and Steve Waksman (eds.). The Sage Handbook of Popular Music. London: Sage, págs. 301-316.

Thompson, Robert F. (2005). Tango. The Art History of Love. Nueva York: Vintage Books.

Vilaltella, Javier G. (2000), "Tango y bolero: apuntes sobre un discurso (no) melodramático", en Michael Rössner (ed.). ¡Bailá! ¡Vení! ¡Volá! El fenómeno tanguero y la literatura. Madrid-Frankfurt: Iberoamericana-Vervuert, págs. 2742. 